\title{
A comparative analysis of air pollution levels during times of international uncertainty: The financial crisis of 2008 and the COVID-19 pandemic of 2020
}

Ammar Vora ${ }^{1}$ and Hillary Hale ${ }^{2}$

\author{
${ }^{1}$ Sir Winston Churchill High School, Alberta, Canada \\ ${ }^{2}$ Institute of Environmental Science, Carleton University, Ottawa, Canada
}

KEYWORDS: air pollution, financial crisis, COVID-19, international uncertainty, recession

\section{INTRODUCTION}

During a crisis, economies stagnate as uncertainty grows about the future state of the world. The financial crisis of 2008 led to a severe recession where the global economy halted for approximately two years, causing unemployment and poverty [1]. Coronavirus disease 2019 (COVID-19), which attacks the respiratory system [2], was first identified in Wuhan, China, in late December of 2019. Within a matter of months, it spread globally causing economies to shut down. As distinct as the financial crisis of $\mathbf{2 0 0 8}$ may seem from the COVID-19 pandemic lockdowns, both have had devastating effects on national economies and industrial production, resulting in an overall decrease in air pollutant emissions such as carbon dioxide $\left(\mathrm{CO}_{2}\right)$ and nitrogen oxides $\left(\mathrm{NO}_{\mathrm{x}}\right)$. Therefore, parallels can be made between air pollution levels during each crisis. Given air pollution rates increased after the financial crisis of 2008 [3], it is likely air pollution will also rise in the aftermath of the COVID-19 pandemic. This study aims to support this argument by analyzing air pollution trends outlined in the results of several published papers.

\section{COMPARING TRENDS IN AIR POLLUTION LEVELS}

\section{The financial crisis of 2008}

During the early 2000s up until 2007, housing prices in the United States market were rising [4]. This created a housing bubble that eventually burst in 2007 , resulting in a recession [1]. As the US economy crashed, many places such as the European Union followed in economic decline [1]. By 2008, some researchers believed the recession was as severe as the Great Depression [1].

A study conducted by Pacca et al. (2019) analyzed shortterm effects on air pollution from several financial crises that took place in the period of 1970 to 2014 [3]. Pollutants were chosen based on atmospheric abundance. $\mathrm{CO} 2$ and NOx emissions were analyzed and data were collected from the World Bank [3]. The time period of the data was split into four decades and the percent changes are shown in Table 1.

Table 1. Percent change in emissions during different decades.

\begin{tabular}{|c|c|c|c|c|}
\hline & 1970s & 1980s & 1990s & 2000s \\
\hline \multirow{2}{*}{$\begin{array}{l}\mathrm{CO}_{2-} \mathrm{pc} \\
\text { growth }\end{array}$} & -0.010 & -0.008 & -0.018 & $-0.041 * * *$ \\
\hline & $(0.046)$ & $(0.012)$ & $(0.012)$ & $(0.006)$ \\
\hline \multirow{2}{*}{$\begin{array}{l}\mathrm{SO}_{2-} \mathrm{pc} \\
\text { growth }\end{array}$} & -0.027 & -0.012 & $-0.023 * *$ & -0.014 \\
\hline & $(0.025)$ & $(0.011)$ & $(0.010)$ & $(0.011)$ \\
\hline \multirow{2}{*}{$\begin{array}{l}\text { NO }_{x-p c} \\
\text { growth }\end{array}$} & $-0.027^{*}$ & $-0.017 * *$ & $-0.013^{*}$ & $-0.038 * * *$ \\
\hline & $(0.014)$ & (0.007) & $(0.007)$ & $(0.008)$ \\
\hline \multirow{2}{*}{$\begin{array}{l}\mathrm{PM}_{2.5-\mathrm{pc}} \mathrm{pc} \\
\text { growth }\end{array}$} & -0.013 & 0.001 & -0.005 & -0.008 \\
\hline & 0.009 & 0.006 & 0.004 & 0.007 \\
\hline
\end{tabular}

Top values display percent change and bottom numbers represent standard errors) [3]. $\mathrm{p}<0.10=*, \mathrm{p}<0.05=* *, \mathrm{p}<0.010=* \star *$

In the 2000s, there was a reduction in $\mathrm{CO}_{2}$ and $\mathrm{NO}_{x}$ concentrations by $4.1 \%$ and $3.8 \%$ respectively [3]. The results support the argument that a decline in economic activity is related with a reduction in air pollutants such as $\mathrm{CO}_{2}$ and $\mathrm{NO}_{x}$. A stagnant economy in 2008 led to lower industrial production and fossil fuel combustion, and therefore, lower air pollution levels. However, the underlying question is, how long does it stay this way?

Pacca et al. (2019) also examined the mid-term effects of financial crises [3]. Over the span of 11 years, with year 0 being the time during a financial crisis, the changes in the levels of $\mathrm{CO}_{2}$ and $\mathrm{NO}_{x}$ were found [3]. Table 2 shows $\mathrm{NO}_{x}$ levels also increased as the percent changes from year 6 (p-value < 0.010 ) and 8 ( $p$-value $<0.10$ ) have statistical significance.

Data from The World Bank on global $\mathrm{CO}_{2}$ emissions show a steady increase in levels from 2004 and up to 2008, as 
Table 2. Mid-term effects of a financial crisis on pollutants.

\begin{tabular}{rcccccccccccc}
\hline & $\mathbf{( 0 )}$ & $\mathbf{( 1 )}$ & $\mathbf{( 2 )}$ & $\mathbf{( 3 )}$ & $\mathbf{( 4 )}$ & $\mathbf{( 5 )}$ & $\mathbf{( 6 )}$ & $\mathbf{( 7 )}$ & $\mathbf{( 8 )}$ & $\mathbf{( 9 )}$ & $\mathbf{( 1 0 )}$ \\
\hline $\mathbf{C O}_{\mathbf{2}}$ & $-0.031 * *$ & -0.019 & -0.017 & 0.033 & $-0.019 *$ & 0.006 & $-0.023^{* *}$ & 0.022 & 0.001 & -0.004 & $-0.028^{* *}$ \\
& $(0.014)$ & $(0.012)$ & $(0.014)$ & $(0.028)$ & $(0.010)$ & $(0.012)$ & $(0.009)$ & $(0.018)$ & $(0.012)$ & $(0.014)$ & $(0.013)$ \\
$\mathbf{N}$ & 5968 & 5815 & 5662 & 5509 & 5357 & 5205 & 5053 & 4901 & 4749 & 4597 & 4445 \\
$\mathbf{S O}_{\mathbf{2}}$ & $-0.034 * * *$ & $-0.034 * * *$ & -0.006 & -0.000 & 0.009 & 0.016 & $0.025 *$ & 0.008 & 0.017 & 0.009 & 0.002 \\
& $(0.010)$ & $(0.008)$ & $(0.010)$ & $(0.008)$ & $(0.008)$ & $(0.015)$ & $(0.015)$ & $(0.011)$ & $(0.012)$ & $(0.010)$ & $(0.010)$ \\
$\mathbf{N}$ & 5660 & 5511 & 5362 & 5213 & 5064 & 4915 & 4766 & 4617 & 4468 & 4319 & 4170 \\
$\mathbf{N O} \mathbf{O}_{\mathbf{x}}$ & $-0.022^{* * *}$ & $-0.023^{* * *}$ & 0.004 & 0.002 & 0.004 & 0.009 & $0.015 * * *$ & 0.006 & $0.019 *$ & 0.009 & 0.005 \\
& $(0.006)$ & $(0.006)$ & $(0.006)$ & $(0.005)$ & $(0.006)$ & $(0.008)$ & $(0.006)$ & $(0.006)$ & $(0.010)$ & $(0.007)$ & $(0.006)$ \\
$\mathbf{N}$ & 5661 & 5512 & 5363 & 5214 & 5065 & 4916 & 4767 & 4618 & 4469 & 4320 & 4171 \\
\hline
\end{tabular}

Top values display percent change and bottom numbers represent standard errors) $[5] . p<0.10=*, p<0.050=* \star, p<0.010=* \star *$.

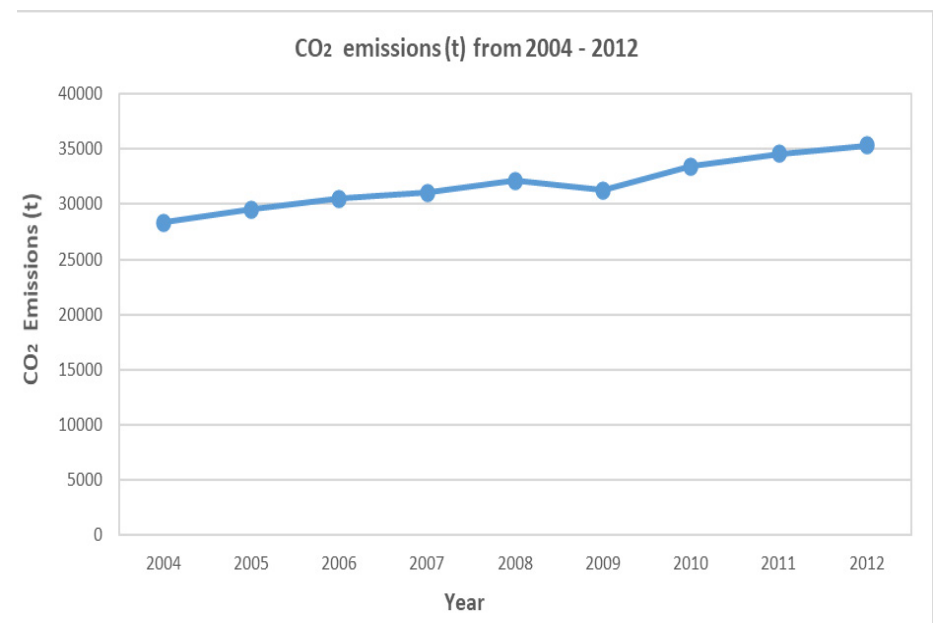

Figure 1. Global $\mathrm{CO}_{2}$ emissions in tonnes (t) [6].

displayed in Figure 1 [6]. During the financial crisis (20082009), $\mathrm{CO}_{2}$ levels dropped as indicated by the dip in the graph. However, after the crisis was resolved in $2009, \mathrm{CO}_{2}$ levels increased. The crisis' effect on air pollution was completely reversed and pollution levels continued to rise (Figure 1). This was likely because international trade and other industries had restarted [7]. The environmental effects caused by the financial crisis of 2008 were short-lived and soon reversed [3]. Due to its similar effects on the economy, the aftermath of the COVID-19 pandemic may have similar outcomes.

\section{COVID-19 pandemic}

COVID-19 was declared an epidemic and a global health concern by the World Health Organization (WHO) on January 30, 2020 [2]. COVID-19 is believed to have emerged from bats; it attacks the respiratory system and can be fatal for people with compromised immune systems [2]. As COVID-19 spread around the globe, international travel, trade, and economies

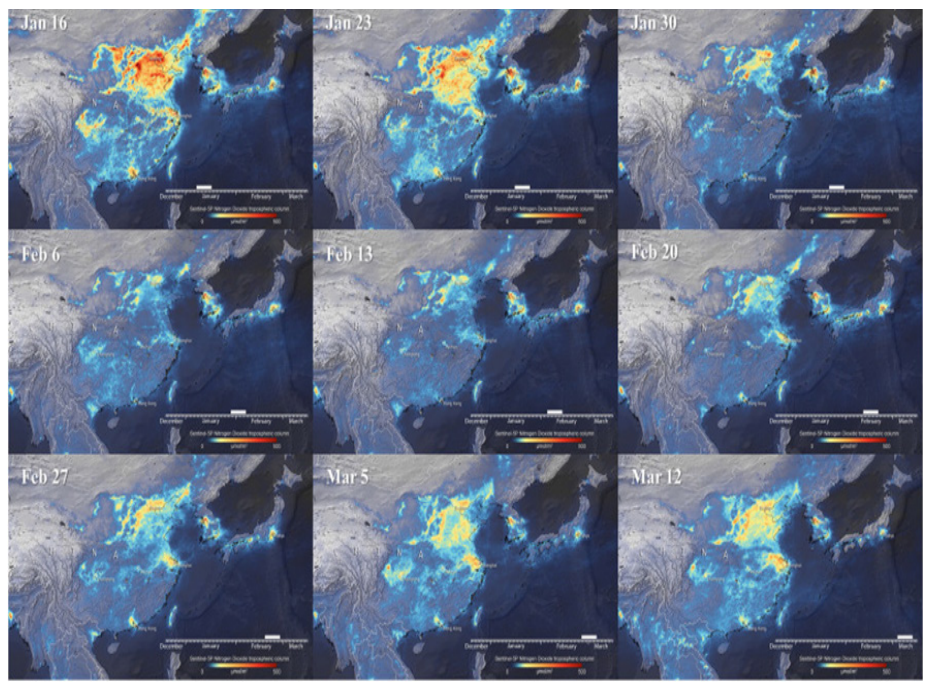

Figure 2. Changes in $\mathrm{NO}_{2}$ levels in the troposphere across China from mid-January to mid-March 2020 [9].

were shut down to reduce the transmission of the disease [8]. As a result, several atmospheric changes have been observed internationally. Therefore, geographically spread-out locations have been analyzed for emission changes caused due to the pandemic.

\section{China}

Through a Sentinel- 5 satellite $\mathrm{NO}_{2}$ levels in the troposphere above China were monitored [9]. A week before China went on full lockdown in January 2020, the highest $\mathrm{NO}_{2}$ levels were observed. Figure 2 shows that as the lockdown progressed, $\mathrm{NO}_{2}$ levels significantly decreased on a weekly basis [9]

\section{Italy}

Comparing the March of 2019 and the March of 2020, emissions of $\mathrm{NO}_{2}$ were reduced by about $20-30 \%$ (Figure 4) [10]. 


\section{United States of America (USA)}

A reduction of $30 \%$ in $\mathrm{NO}_{2}$ emissions has been observed over the USA using the AURA satellite [10]. $\mathrm{NO}_{2}$ levels have decreased, similar to the reduction observed during the financial crisis of 2008.

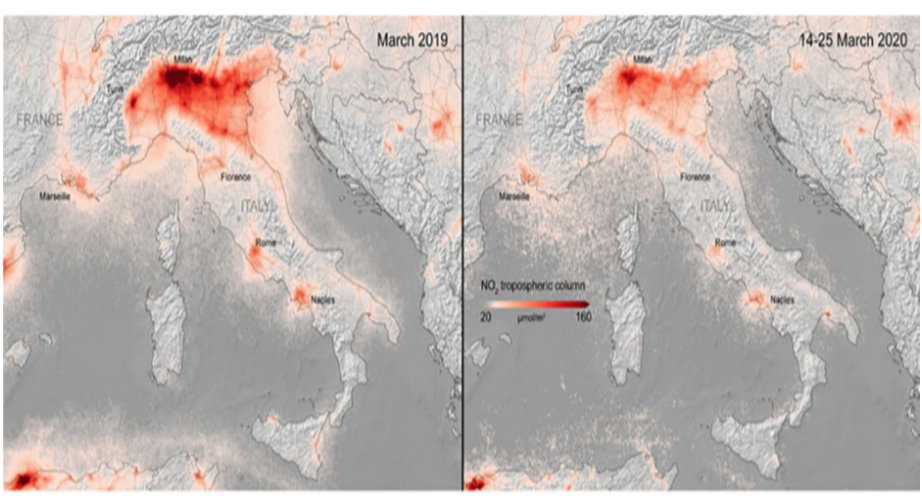

Figure 3. Changes in $\mathrm{NO}_{2}$ levels before lockdown and during lockdown (March 2019 and March 2020, respectively) in Italy [10].

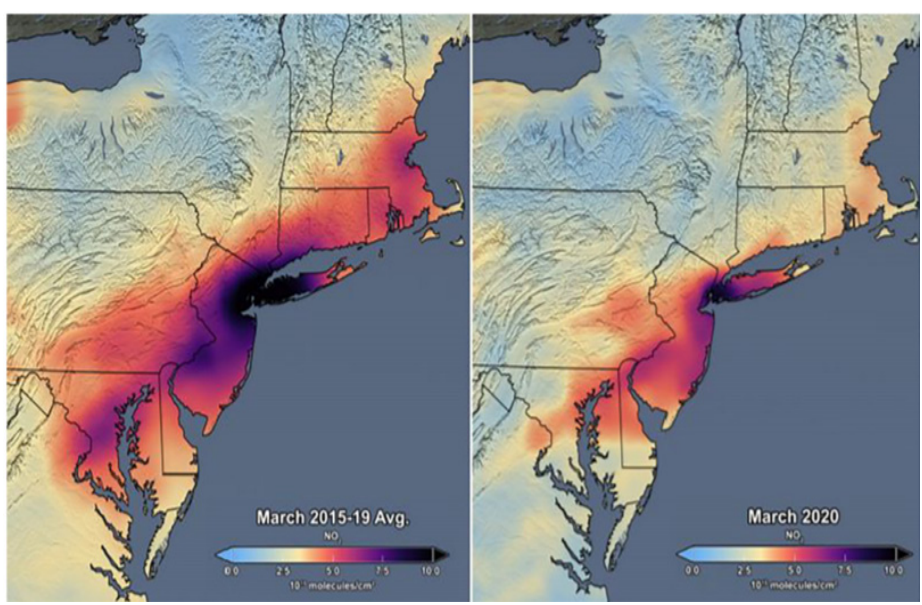

Figure 4. Changes in $\mathrm{NO}_{2}$ levels above the Northeast USA before (March averages from 2015-2019) and after lockdown (March 2020) [10].

\section{Global carbon emissions}

Global carbon emissions have also decreased during the COVID-19 pandemic. A study conducted by Quéré et al. (2020) presented the reduction of $\mathrm{CO}_{2}$ levels during the COVID-19 pandemic using a confinement index $(\mathrm{Cl})$ [11]. By mapping the impact of governmental COVID-19 policies, the $\mathrm{Cl}$ was used to estimate carbon emissions at a country-wide scale [11]. Annual mean daily emissions of $\mathrm{CO}_{2}$ from 1970-April 2020 were plotted, with an uncertainty of $\pm 5 \%$ [11]. Similar to the financial crisis of 2008, the COVID-19 pandemic caused a reduction in carbon emissions.

Several other studies have also found that air pollution levels have decreased as a result of the COVID-19 pandemic. One such study, conducted by Venter et al. (2020), analyzes the impact of COVID-19 lockdown policies on $\mathrm{NO}_{2}$ levels in 34 countries, spanning five continents [12]. By comparing satellite data of pollutant levels during January-May 2020 to the three-year average of pollutant levels calculated during the same time-frame, a decrease of $60 \%$ in $\mathrm{NO}_{2}$ levels was found [12]. Ju et al. (2020) have investigated changes in air pollution levels in Korea caused by the COVID-19 outbreak [13]. Their study concludes that there has been $20.41 \%$ reduction in $\mathrm{NO}_{2}$ in 2020. This was found by conducting a paired T-test between the pollution levels from December 2019 to April 2020 and the previous four-year averages for the same time period.
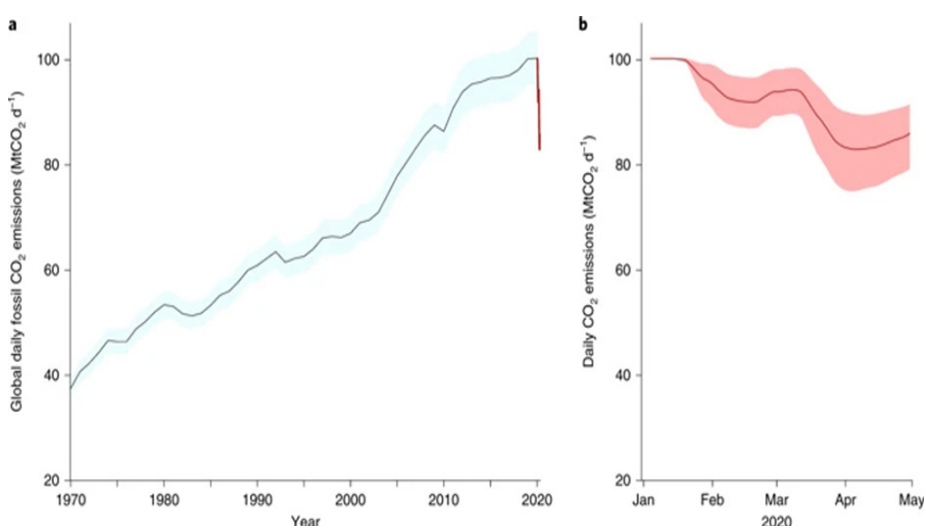

Figure 5. (a) Global $\mathrm{CO}_{2}$ emissions from 1970-2019 with an uncertainty of $\pm 5 \%$. (b) Emission estimates in the red line [11].

\section{What does this mean?}

A pattern can be seen in the air pollution levels when comparing the financial crisis of 2008 and the COVID-19 pandemic. There was a sharp decline in polluting gases such as $\mathrm{CO}_{2}$ and $\mathrm{NO}_{x}$ during the financial crisis $[3,6]$. However, soon after the passing of the crisis, these air pollutant levels rose significantly [3]. A similar dip in air pollutant levels can be observed through satellite images during the COVID-19 pandemic (Fig 2-4). $\mathrm{NO}_{2}$ levels in countries around the world have decreased and a swift reduction in global $\mathrm{CO}_{2}$ emissions can be observed. Some even question the reduction in emissions to be a "blessing in disguise" [10]. However, the cause for concern is after the economic crises are over. 
Emissions decrease as economic activity slows during times of international uncertainty. Yet, it is likely air pollution levels will skyrocket after the passing of the global pandemic, similar to previous financial crises.

\section{Next steps}

Air pollution is one of the major factors leading to climate change. The Intergovernmental Panel on Climate Change estimates that at the current rate of emissions of air pollutants, global warming will reach $1.5^{\circ} \mathrm{C}$ between 2030 and 2052 [14]. Experts believe this will result in loss of species, ecological degradation, and a higher spread of invasive species [14]. Integrating low carbon footprint technologies like electric cars and solar-powered airplanes [15] will help reduce emissions. The aftermath of the global pandemic should be viewed as an opportunity to implement drastic changes in global policies and industrial practices, in an effort to reduce global air pollution levels.

\section{ACKNOWLEDGMENTS}

I wish to express my great appreciation to Ms. Hillary Hale, my mentor, for providing extremely helpful feedback and guidance throughout this paper. Thank you for your willingness and time. I would like to thank STEMpowerment for providing an opportunity to gain skills in the world of research and literature.

\section{REFERENCES}

1. Verick S, Islam I. The Great Recession of 2008-2009: Causes, Consequences and Policy Responses [Internet]. SSRN. 2010 [cited 2020Jun16]; IZA Discussion Paper No. 4934. Available from: https://papers.ssrn.com/sol3/ papers.cfm?abstract_id $=1631069$

2. Guo Y-R, Cao Q-D, Hong Z-S, Tan Y-Y, Chen S-D, Jin H-J, et al. [Internet]. The origin, transmission and clinical therapies on coronavirus disease 2019 (COVID-19) outbreak - an update on the status. 2020 [cited 2020Jun16]; Military Med Res 7, 11. Available from: https://rdcu.be/b4Wpe

3. Pacca L, Antonarakis A, Schröder P, Antoniades A. The effect of financial crises on air pollutant emissions: An assessment of the short vs. medium-term effects [Internet]. Science of The Total Environment. Elsevier; 2019 [cited 2020Jun16];698, Article No. 133614. Table 1, Percent change in emissions during different decades; Table 2, Mid-term effects of a financial crisis on pollutants. Available from: https://www.sciencedirect. com/science/article/pii/S0048969719335399?via=ihub

4. Glaeser EL, Sinai TM. Housing and the financial crisis.
Chicago, Illinois: University of Chicago Press; 2013. https://www.nber.org/books-and-chapters/housingand-financial-crisis/supply-side-housing-boom-and-bust2000s

5. L. Laeven, F. Valencia. Systemic Banking Crises Revisited Working Paper No. 18/206 IMF, Washington DC (2018).

6. $\mathrm{CO} 2$ emissions (kt) [Internet]. Data. Figure 2, Global $\mathrm{CO} 2$ emissions. Available from: https://data.worldbank.org/ indicator/EN.ATM.CO2E.KT?contextual=default

7. Jiang $X$, Guan $D$. The global $\mathrm{CO} 2$ emissions growth after international crisis and the role of international trade [Internet]. Energy Policy. Elsevier; 2017 [cited 20200ct29]. Available from: https://www.sciencedirect. com/science/article/abs/pii/S0301421517304883

8. Nicola M, Alsafi Z, Sohrabi C, Kerwan A, Al-Jabir A, losifidis C, et al. [Internet]. The socio-economic implications of the coronavirus pandemic (COVID-19): A review. IJS Publishing Group Ltd. Published by Elsevier Ltd.; 2020 [cited 20200ct25]. Available from: https:// www.ncbi.nlm.nih.gov/pmc/articles/PMC7162753/

9. Wang Q, Su M. A preliminary assessment of the impact of COVID-19 on environment - A case study of China [Internet]. Dimensions. 2020 [cited 2020Jun16];728(4). Figure 2, Changes in NO2 levels in the troposphere. Available from: https://app.dimensions. ai/details/publication/pub.1126894659?search_ text=air+pollution+after+covid+19

10. Muhammad S, Long X, Salman M. COVID-19 pandemic and environmental pollution: A blessing in disguise? [Internet]. Dimensions. 2020 [cited 2020Jun29];728, Article No. 138820. Figure 3, Changes in NO2 levels above Italy; Figure 4, Changes in NO2 levels above Northeast US. Available from: https://app.dimensions. ai/details/publication/pub.1126822876?search_ text=covid+19+and+pollution

11. Quéré $C L$, Jackson RB, Jones MW, Smith AJP, Abernethy $\mathrm{S}$, Andrew RM, et al. Temporary reduction in daily global CO 2 emissions during the COVID-19 forced confinement [Internet]. 2020 [cited 2020Jun29]; Nat. Clim. Chang. 10, 647-653. Figure 5, Global CO2 emissions with emission estimates in the red line. Available from: https://www. nature.com/articles/s41558-020-0797-x

12. Venter ZS, Aunan K, Chowdhury S, Lelieveld J. COVID-19 lockdowns cause global air pollution declines [Internet]. 2020 [cited 2021Apr13]. Available from: https://www. pnas.org/content/117/32/18984

13. Ju MJ, Oh J, Choi Y-H. Changes in air pollution levels after COVID-19 outbreak in Korea [Internet]. Science of The Total Environment. Elsevier; 2020 [cited 2021Apr13]. Available from: https://www.sciencedirect.com/science/ article/pii/S0048969720350506?via\%3Dihub

14. Allen MR, Babikar M, Chen $Y$, Coninck Hde, Connors $\mathrm{S}$, Diemen Rvan, et al. Summary for Policymakers [Internet]. Global Warming of $1.5^{\circ} \mathrm{C}$. 2018 [cited 2020Jul14]. Available from: https://www.ipcc.ch/sr15/ chapter/spm/ 